\title{
REFERÊNCIAS EM LIVROS E ARTIGOS DE PERIÓDICOS: UMA COMPARAÇÃO DE ESTILOS
}

\author{
JULIO CÉSAR LIMA SAMPAIO* \\ MAGNAURA MENDONÇA \\ MARILENE DE SENA E SILVA ${ }^{* * *}$ \\ TALIA RAQUEL OLIVEIRA CARVALHO ${ }^{* * *}$
}

\begin{abstract}
RESUMO
Referenciar é identificar individualmente um documento com base em orientações de estilos que orientam entre outras coisas a citação e as referências. O objetivo do artigo foi identificar os principais estilos, suas características na descrição de referências como a formatação da autoria pessoa física; uso do "et al"; destaque tipográfico a abreviação de títulos de periódicos. Foram analisados oito estilos que em sua maioria possuem custo para acesso ao texto completo. O sistema autor-data é comum; os estilos variam muito em relação ao uso do "et al"; a caixa alta foi observada na ISO 690 e NBR 6023; os estilos APA, CSE, MLA, Chicago, Harvard e Vancouver são simples; favorecem o conteúdo e são de custo acessível.
\end{abstract}

PALAVRAS-CHAVE: Referências. Estilos de referência. Estilos de citação.

REFERENCES IN BOOKS AND JOURNAL ARTICLE: A STYLES COMPARISON

\begin{abstract}
Referencing is individually identifying a document based on style guidelines that guide, among other things, quote and references. The objective of the article was to identify the main styles, their characteristics in the description of references such as the formatting of the individual authorship; use of the "et al"; typographic highlight to the abbreviation of journal titles. Were analyzed eight styles that mostly have cost to access the full text. The author-date system is common; the styles vary a lot about "et al" use; the caps lock was observed in ISO 690 and NBR 6023; the APA, CSE, MLA, Chicago, Harvard, and Vancouver styles are simple; they favor the content and are affordable cost.
\end{abstract}

KEYWORDS: References. Reference styles. Citation Styles.

* Bibliotecário da Fundação de Dermatologia Tropical e Venereologia "Alfredo da Matta", Manaus, AM, Brasil.

** Bibliotecária da Empresa Jornada Participações, AM, Brasil

* Gerente de Residência Médica da Fundação Hospital Adriano Jorge, Manaus, AM, Brasil

Graduanda em Biblioteconomia pela Universidade Federal do Amazonas-UFAM 


\section{INTRODUÇÃO}

Documento é qualquer suporte (livro impresso, e-book, DVD, $C D$, registro audiovisual, tridimensional e outros) que contenha informação registrada, formando uma unidade, que possa servir para consulta, estudo ou prova para fundamentar ou refutar ideias, conceitos e outros. (ASSOCIAÇÃO BRASILEIRA DE NORMAS TÉCNICAS, 2019; FURASTÉ, 2004).

Nos textos acadêmicos, a fim de se evitar o plágio, dar crédito às ideias de outros autores, facilitar que qualquer pessoa encontre os documentos referenciados e revestir o trabalho de consistência e credibilidade, as ideias, conceitos e conclusões dos outros autores devem ser citadas no texto com sua respectiva referência, geralmente elaborada em formato de listas de referências inseridas ao final do texto e construídas conforme um estilo definido. (UNIVERSITAT D'ALICANTE; BIBLIOTECA UNIVERSITARIA, 2017).

Os estilos visam estabelecer os elementos incluídos, fixando a ordem dos mesmos e estabelecendo convenções para a transcrição e apresentação da informação originada do documento. Destinam-se também à orientação para a preparação e compilação de referências de material utilizado para a produção de documentos e para inclusão em bibliografias, resumos, resenhas recensões e outros Os estilos variam conforme a área do conhecimento e influências. (ASSOCIAÇÃO BRASILEIRA DE NORMAS TÉCNICAS, 2018; FURASTÉ, 2004).

Assim, o objetivo deste trabalho foi o de listar os principais estilos utilizados para elaboração de citações e referências, identificando suas características básicas com destaque para as semelhanças e diferenças utilizando os tipos documentais livros como um todo e artigos de periódicos como exemplos, visto que a utilização de mais tipos documentais tornaria o artigo extenso e cansativo.

\section{ESTILOS UTILIZADOS EM CITAÇÕES E REFERÊNCIAS}

Os estilos mais utilizados em citações e referências são os da ISO 690:2010 (E) aplicáveis a qualquer área do conhecimento; estilo da Associação Americana de Psicologia (APA) utilizado em psicologia, educação e ciências sociais; o Modern Language Association (MLA) utilizado em ciências sociais, humanidades, língua e literatura; o The Chicago Manual of Style Online aplicado nas áreas de história, humanidades, arte, literatura e ciências sociais; estilo de Harvard empregado na física e nas ciências naturais e sociais; o The Council of Science Editors (CSE) voltado para as áreas de biologia e ciências da natureza e o estilo Vancouver, utilizado especificamente 
na biomedicina, além é claro da NBR 6023, construída sob as bases da ISO 690:2010 (E) é aplicável a qualquer disciplina (Quadro 1). (AMERICAN PSHYCOLOGICAL ASSOCIATION, 2020; INTERNATIONAL ORGANIZATION FOR STANDARDIZATION, 2010; MODERN LANGUAGE ASSOCIATION, 2016; UNIVERSITAT D'ALICANTE; BIBLIOTECA UNIVERSITARIA, 2017; UNIVERSITY OF CHICAGO, 2017).

Quadro 1 - Estilos, área de aplicação, forma de acesso e fonte

\begin{tabular}{|c|c|c|c|c|}
\hline Item & Estilo & $\begin{array}{l}\text { Área de } \\
\text { aplicação }\end{array}$ & $\begin{array}{c}\text { Forma de } \\
\text { Acesso }\end{array}$ & Fonte \\
\hline 1 & $\begin{array}{c}\text { ISO } \\
690: 2010(E)\end{array}$ & $\begin{array}{l}\text { Qualquer área } \\
\text { do } \\
\text { conhecimento }\end{array}$ & Pago & www.abnt.org.br \\
\hline 2 & NBR 6023:2018 & $\begin{array}{c}\text { Qualquer área } \\
\text { do } \\
\text { conhecimento }\end{array}$ & Pago & www.abnt.org.br \\
\hline 3 & $\begin{array}{l}\text { Associação } \\
\text { Americana de } \\
\text { Psicologia } \\
\text { (APA) }\end{array}$ & $\begin{array}{c}\text { Psicologia, } \\
\text { educação e } \\
\text { ciências sociais }\end{array}$ & Pago & $\begin{array}{c}\text { https://apastyle. } \\
\text { apa.org/ }\end{array}$ \\
\hline 4 & $\begin{array}{c}\text { Modern } \\
\text { Language } \\
\text { Association } \\
\text { (MLA) }\end{array}$ & \begin{tabular}{|c|} 
Ciências \\
sociais, \\
humanidades, \\
língua e \\
literatura
\end{tabular} & Pago & $\begin{array}{l}\text { https://style.mla.org } \\
\text { /works-cited-a- } \\
\text { quick-guide/ }\end{array}$ \\
\hline 5 & $\begin{array}{c}\text { The Chicago } \\
\text { Manual of Style } \\
\text { Online }\end{array}$ & $\begin{array}{c}\text { História, } \\
\text { humanidades, } \\
\text { arte, literatura e } \\
\text { ciências sociais }\end{array}$ & Pago & $\begin{array}{c}\text { https://www.chicago } \\
\text { manualofstyle.org/ } \\
\text { home.html }\end{array}$ \\
\hline 6 & Harward $^{1}$ & $\begin{array}{c}\text { Física e nas } \\
\text { ciências } \\
\text { naturais e } \\
\text { sociais } \\
\end{array}$ & Free & $\begin{array}{l}\text { https://guides.library } \\
\text { harvard.edu/ } \\
\text { cite/guides }\end{array}$ \\
\hline 7 & $\begin{array}{c}\text { Council of } \\
\text { Science Editors } \\
\text { (CSE) }\end{array}$ & $\begin{array}{l}\text { Biologia e } \\
\text { ciências da } \\
\text { natureza }\end{array}$ & Pago & $\begin{array}{c}\text { https://www.council } \\
\text { scienceeditors.org/ } \\
\text { publications/scientific } \\
\text {-style-and-format/ }\end{array}$ \\
\hline 8 & Vancouver & Biomedicina & Free & $\begin{array}{c}\text { http://www.icmje.org } \\
\text { /recommendations/ } \\
\text { ou } \\
\text { https://www.nlm.nih. } \\
\text { gov/bsd/uniform_ } \\
\text { requirements.html }\end{array}$ \\
\hline
\end{tabular}

Fonte: O autor, 2020 


\subsection{ISO 690:2020(E)}

A norma ISO 690:2010(E) Information and Documentation Guidelines for bibliographic references and citations to information é uma norma internacional criada, disponibilizada e mantida pela International Standards Organization (ISO) que estabelece as diretrizes para citações e referências, bem como as convenções para a transcrição e apresentação da informação proveniente dos mais diversos tipos de documentos (monografias, publicações seriadas, patentes, materiais cartográficos, recursos eletrônicos, música, fotografias, audiovisuais e outros). É aplicável a qualquer área do conhecimento, exceto para citações legíveis por máquina e citações legais por terem seus próprios padrões. (INTERNATIONAL ORGANIZATION FOR STANDARDIZATION, 2010; UNIVERSITAT D'ALICANTE; BIBLIOTECA UNIVERSITARIA, 2017).

A atualização da norma é feita por meio de comissões em intervalos irregulares. $\mathrm{O}$ acesso ao texto integral da norma é pago e de custo elevado em relação aos outros estilos. (INTERNATIONAL ORGANIZATION FOR STANDARDIZATION, 2010; ISO 690, 2012; UNIVERSITAT D'ALICANTE; BIBLIOTECA UNIVERSITARIA, 2017).

\subsection{NBR 6023:2018 - Informação e documentação - Referências - Elaboração}

A NBR 6023, versão de 2018, é uma norma criada e disponibilizada pela Associação Brasileira de Normas Técnicas aplicável em qualquer área do conhecimento. A sua versão anterior foi construída com base na ISO 690 e 690-2, ambas na versão de 1997 e que foram substituídas pela ISO 690:2010(E). A NBR 6023 teve em sua história cinco versões (1970, 1974, 1978, 1989 e 2000). Atualmente está disponível na sétima versão (2018). (ASSOCIAÇÃO BRASILEIRA DE NORMAS TÉCNICAS, 2018; BIBLIOTECA JOSÉ DE ALENCAR, 2019).

O texto atual não faz menção ao uso da ISO 690 para elaboração do novo texto. A afirmação de seu "parentesco" com a ISO 690 faz-se por analogia devido a sua similaridade em muitos aspectos. (ASSOCIAÇÃO BRASILEIRA DE NORMAS TÉCNICAS, 2018; FURASTÉ, 2004).

Em relação às normas existentes no Brasil (Normas Compulsórias, Referendadas, Registradas e Normas Probatórias), a NBR 6023 norma é de uso voluntário e, portanto, não estão sujeitas à fiscalização e talvez essa seja a razão por ela ser adotada 
por uma parte dos editores, ressalvadas algumas exceções. (MONTEIRO, 1997).

O processo de elaboração de uma norma ABNT é extremamente burocrático. Inicia a partir de uma demanda apresentada por qualquer pessoa, empresa, entidade ou organismo regulamentador envolvidos com 0 assunto a ser normalizado. A demanda é então analisada e se pertinente, o Comitê Técnico que o insere ao Programa de Normalização Setorial até ser discutido pelas Comissões de Estudo com a participação aberta de parte da sociedade interessada (associado ou não) até atingir o consenso e ser finalmente publicada. (ASSOCIAÇÃO BRASILEIRA DE NORMAS TÉCNICAS, 2014).

\subsection{Associação Americana de Psicologia - APA}

A Associação Americana de Psicologia (APA) foi fundada em 1892 na Universidade de Clark e tem como objetivo representar a psicologia nos Estados Unidos da América e no Canadá. Possui vários produtos e publicações na área da psicologia disponibilizada para seus membros. Entre as publicações da APA, encontra-se o APA Style utilizado para uma comunicação acadêmica concisa, poderosa e persuasiva por vários escritores em várias disciplinas ao redor do mundo por meio da padronização da descrição física de vários tipos documentais: artigo de periódico e de revista; artigo de jornal; livro no todo; capítulo de livro; entradas de dicionários; relatório governamental; vídeos do youtube; tweet e post no Facebook. (AMERICAN PSYCHOLOGICAL ASSOCIATION, 2020a).

O conteúdo integral só é possível da aquisição do livro Publication Manual of the American Psychological Association que está na sua sétima edição. No entanto, é possível ver algumas orientações básicas e exemplos desse estilo acessando o link Style Guidelines by Topic, tais como: formato do documento, tabelas e figuras, linguagem livre de preconceito, gramática, referências e citações no texto. (AMERICAN PSYCHOLOGICAL ASSOCIATION, 2020b).

No item Referências há um item chamado de The Essentials onde é possível encontrar os Princípios básicos das entradas nas listas de referências, Trabalhos incluídos nas listas, Elementos da referência, Exemplos de referência mais comuns e outros. As orientações sobre a elaboração de referências e citações estão nos capítulos 9 e 10 do livro da APA. (AMERICAN PSYCHOLOGICAL ASSOCIATION, 2020b). 


\subsection{Modern Language Association (MLA)}

Criado em 1931 pelo diretor-executivo da MLA Carleton Brown e por Cyril Arthur Pierenboom, o estilo MLA é um sistema para documentar fontes em qualquer tipo documental utilizado por mais de meio século em sala de aula em todo o mundo e também por estudiosos, editores de periódicos, editoras acadêmicas e comerciais nas áreas de ciências sociais, humanidades, língua e literatura. (MODERN LANGUAGE ASSOCIATION; THE MLA STYLE CENTER, 2020).

Figura 1 - Parte da primeira versão do estilo MLA publicado em 1931 sob o título "Style Sheet for PMLA

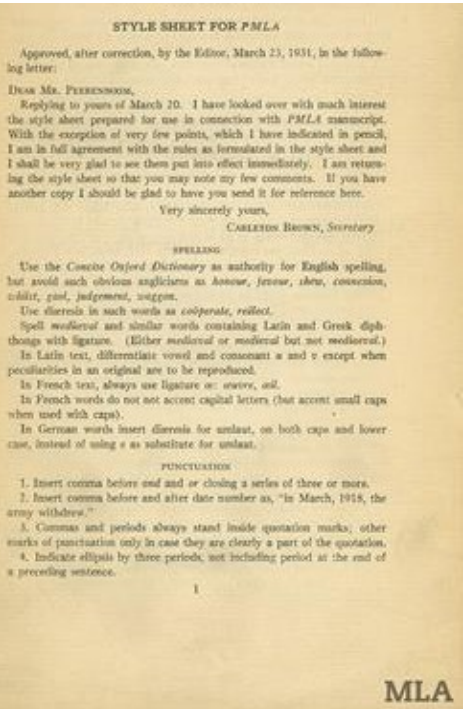

Fonte: MODERN LANGUAGE ASSOCIATION; THE MLA STYLE CENTER, 2020

O acesso ao conteúdo completo do estilo é possível através da aquisição (custo em dólar, mas relativamente acessível comparando-se com a ISO 690 e NBR 6023) da oitava edição do livro MLA Handbook publicado em 2016 e disponível no formato impresso ou digital pelos sistemas Kindle, Apple, Kobo e Nook. (MODERN LANGUAGE ASSOCIATION, 2020).

No site é possível acessar um guia rápido contendo alguns exemplos utilizados pelo MLA, assim como verificar as diretrizes sobre formatação de trabalhos de pesquisa; respostas às perguntas feitas aos editores do MLA; obter amostra de trabalhos de pesquisa, 
recursos didáticos e dicas de escrita (Figura 2). (MODERN LANGUAGE ASSOCIATION, 2020; THE MLA STYLE CENTER, 2020).

Figura 2 - Exemplo do guia rápido do estilo MLA de um ensaio em uma coleção de livros com detalhe para a referência ao final
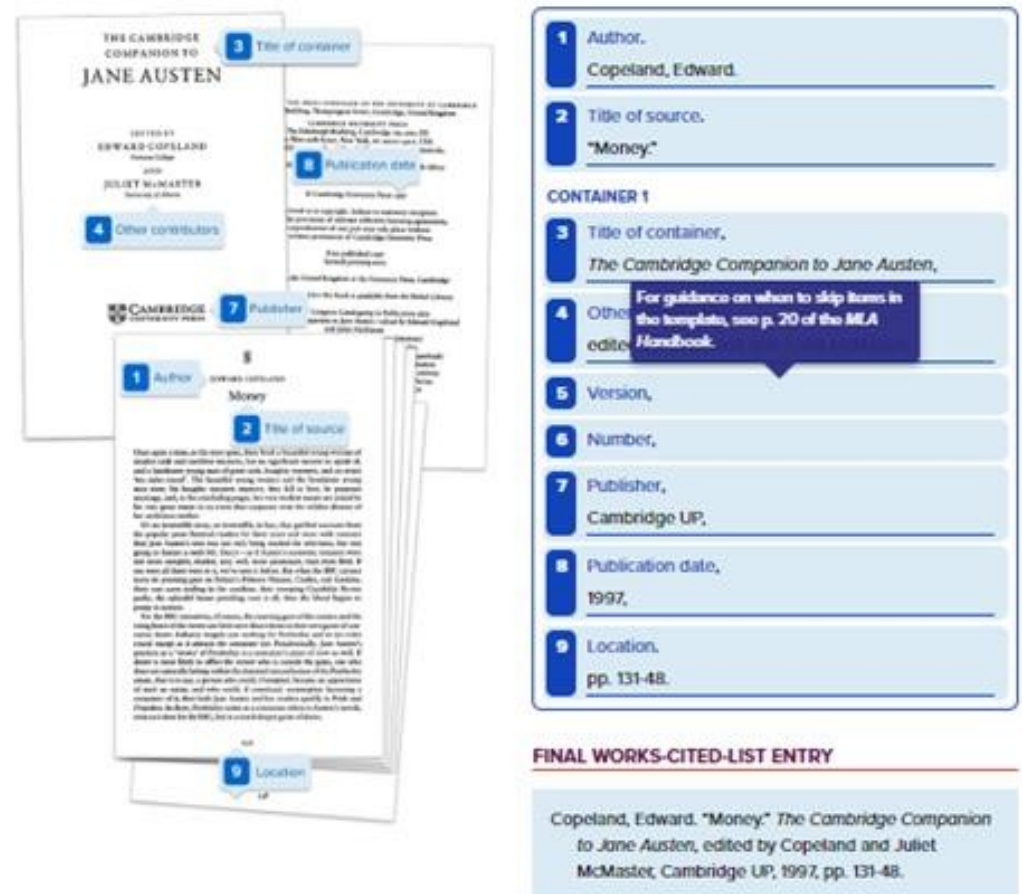

Fonte: (THE MLA STYLE CENTER, 2020)

\subsection{The Chicago Manual of Style Online (Chicago Style)}

O primeiro formato do Chicago Style iniciou em 1891 (mais de cem anos) na University of Chicago Press no trabalho de correção ortográfica e edições de inconsistências estilísticas feitas por revisores cujo objetivo era elaborar um panfleto contendo o conjunto de regras ao processo de edição e revisão para ser divulgada à comunidade universitária. (THE CHICAGO MANUAL OS STYLE ONLINE, 2017; UNIVERSITY OF CHICAGO, 2017).

Alguns anos mais tarde, em 1906, o panfleto evoluiu para um livro e 114 anos depois, o estilo já está na sua $17^{a}$ edição contendo mais de mil páginas, tornando-se o trabalho de referência oficial 
para autores, editores, revisores, indexadores, redatores, designers e editores nas áreas de história, humanidades, arte, literatura e ciências sociais. Evolução que só foi possível à administração contínua da renomada equipe editorial de Chicago, e apoiada pela dinâmica flexível que aproveita as sugestões e solicitações dos muitos leitores do Manual por meio de inúmeras rodadas de intensa investigação, feedback e debate. (THE CHICAGO MANUAL OS STYLE ONLINE, 2017).

O acesso ao texto completo faz-se pela aquisição (compra) online do livro The Chicago Manual Style. O site disponibiliza parte das orientações de forma gratuita no Citation Quick Guide, ambos disponíveis no link https://www.chicagomanualofstyle.org/book/ed17/ frontmatter/toc.html (Figura 3).

Figura 3 - Print de parte da tela com orientações de referências e citações disponíveis no Citation Quick Guide

Notes

1. Susan Satterfield, "Livy and the Pax Deum," Classical Philology 111, no. 2 (April 2016): 170.

2. Shao-Hsun Keng, Chun-Hung Lin, and Peter F. Orazem, "Expanding College Access in Taiwan, 1978-2014: Effects on Graduate Quality and Income Inequality," Journal of Human Capital 11, no. 1 (Spring 2017): 9-10, https://doi.org/10.1086/690235.

3. Peter LaSalle, "Conundrum: A Story about Reading," New England Review 38, no. 1 (2017): 95, Project MUSE.

Shortened notes

4. Satterfield, "Livy," 172-73.

5. Keng, Lin, and Orazem, "Expanding College Access," 23.

6. LaSalle, "Conundrum," 101.

Book

Chapter or other part of an edited book

Tranalated book

E-book

journal article

Newu or magatine article

Book review

Interview

Thesis or dissertation

Website content

Social media content

Personal communication

Bibliography entries (in alphabetical order)

Keng, Shao-Hsun, Chun-Hung Lin, and Peter F. Orazem. "Expanding College Access in Taiwan, 1978-2014: Effects on Graduate Quality and Income Inequality." Journal of Human Capital 11, no. 1 (Spring 2017): 1-34. https://doi.org/10.1086/690235.

LaSalle, Peter. "Conundrum: A Story about Reading." New England Review 38, no. 1 (2017): 95-109. Project MUSE.

Satterfield, Susan. "Livy and the Pax Deum." Classical Philology 111, no. 2 (April 2016): 165-76. 


\subsection{Harvard Referencing}

O estilo de citação e referências Harward, comumente chamado de Harvard Referencing System ou "Author-date Referencing" é o estilo muito usado por estudantes universitários das áreas de física e nas ciências naturais e sociais. (CHERNIN, 1988; CITATION..., 2020).

Apesar do nome, não possui nenhuma ligação oficial com a Universidade de Harvard. A própria Universidade de Harvard considera imprópria a vinculação do nome da universidade ao estilo, pois o nome Harvard seria apenas outro nome dado ao sistema autor/data entre parêntesis, por exemplo (Robbins 1987) utilizado também em outros formatos e cujo estilo começou a ser usado no final do século $19 \mathrm{com}$ a participação de alguns professores da Universidade de Harvard e que emprestaram o nome ao sistema utilizado principalmente na Inglaterra e nos países da Comunidade Britânica das Nações (Commonwealth). (CHERNIN, 1988; CITATION..., 2020; UNIVERSITY LIBRARY, 2019).

Para acessar o estilo Harvard não é necessária a compra de livro ou assinatura de alguma base. O próprio site da instituição (https://guides.library.harvard.edu/cite/guides) fornece alguns exemplos básicos de alguns tipos de documentos além de links úteis para outros estilos e outros textos (Figura 4), (CITATION ..., 2020).

Figura 4 - Print de parte das orientações disponíveis gratuitamente pela Universidade de Harvard
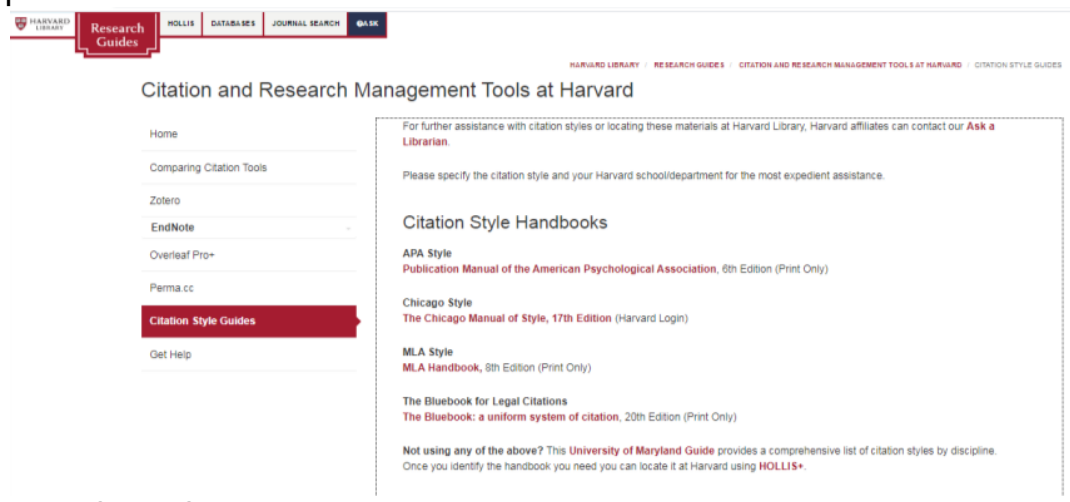

Fonte: CITATION ..., 2020. 


\subsection{Council of Science Editors (CSE)}

Segundo o próprio Council of Science Editors (CSE), este estilo é o mais reconhecido e utilizado por autores, editores, estudantes e tradutores em todas as áreas da ciência e áreas afins. (COUNCIL OF SCIENCE EDITORS, 2020).

O acesso ao conteúdo completo das regras é possível através da aquisição dos direitos de uso do livro Scientific Style and Format que está na sua oitava edição. No link https://www.scientificstyleand format.org/Tools/SSF-Citation-Quick-Guide.html é possível verificar alguns exemplos de referências e citações para artigos de periódicos, livros, dissertações e teses e outros. (COUNCIL OF SCIENCE EDITORS, 2020).

\subsection{Estilo de Vancouver}

Criada em 1978 por um grupo de editores de periódicos biomédicos, a norma ou estilo de Vancouver é um conjunto de regras para a publicação de manuscritos especificamente na área biomédica elaborada com base no protocolo NISO Z39.29-2005(R2010) sobre referências bibliográficas e na adaptação feita pela National Libary of Medicine (NLM) detalhadas no Citing Medicine. (GOSLING, 1979; NATIONAL INFORMATION STANDARDS INSTITUTE, 2010; PATRIAS, 2007).

O Uniform Requirements for Manuscripts Submitted to Biomedical Journals (Vancouver style) foi concebido motivado pela queixa de muitos autores em relação aos editores sobre a demora ou a rejeição de manuscritos. Uma das reclamações mais comuns era a falta de consistência entre os estilos usados pelas diversas revistas, visto que os dois estilos em vigor à época eram o AUTOR-DATA, com as referências listadas em ordem alfabética (Estilo de Harward), e o sistema numérico, com as referências listadas e numeradas na ordem em que elas eram citadas no texto. (SHERRINGTON, 1982; THE VANCOUVER STYLE, 1978).

O passo definitivo em direção à uniformidade foi o estabelecimento de um sistema único que iniciou em 1970 quando um grupo de editores de 30 periódicos clínicos americanos concordou em usar o estilo de Index Medicus e três anos mais tarde, editores de um grupo de periódicos biomédicos tiveram atitude semelhante. (BRKIC; PEJIC, 1996; STYLE..., 1970).

Em janeiro de 1978, essas propostas foram estendidas internacionalmente, quando um grupo de editores dos maiores 
periódicos biomédicos dos EUA, Canadá e Grã-Bretanha, reuniram-se em Vancouver e produziram o conjunto preliminar de requisitos uniformes para manuscritos, que foi revisado no ano seguinte em Montreal (Canadá) consolidando assim o que viria a ser a Norma de Vancouver (NV). (INTERNATIONAL STEERING COMMITTEE OF MEDICAL EDITORS, 1978, 1979; THEDECLARATION OF VANCOUVER, 1979).

O acesso ao estilo é gratuito e atualmente, cabe ao National Center for Biotechnology Information (NCBI) a atualização e divulgação destas normas que possuem constante atualização para contemplar os diferentes suportes. O NCBI disponibiliza um resumo da norma no Samples of Formatted References for Authors of Journal Articles e, caso necessário, o Citing Medicine apresenta detalhes da norma de Vancouver. (NATIONAL LIBRARY OF MEDICINE, 2018; PATRIAS, 2007).

O objetivo deste artigo é informar e refletir sobre as características básicas, semelhanças e diferenças significativas entre os estilos ISO 690:2010(E), NBR 6023:2018, Associação Americana de Psicologia (APA), Modern Language Association (MLA), The Chicago Manual of Style Online, Harward, Council of Science Editors (CSE) e Vancouver aplicáveis às referências de livro no todo e artigo de periódico.

\section{CITAÇÃO}

Similar ao que ocorre com a pontuação, ressalvadas as devidas diferenças, foram identificados três estilos similares: ISO 690, NBR 6023 e CSE. Ambos possibilitam duas opções de estilos: numérico e autor-data. Em relação à NBR 6023, ressalta-se a localização do texto com as orientações. Na ISO 690, a regra sobe a citação está no próprio corpo da norma, enquanto a ABNT possui uma norma específica sobre o assunto que é a NBR 10520 que está em vigor desde 2002. (ASSOCIAÇÃO BRASILEIRA DE NORMAS TÉCNICAS, 2002, 2018; INTERNATIONAL ORGANIZATION FOR STANDARDIZATION, 2010).

Os estilos APA, MLA, Chicago e Harvard utilizam apenas o sistema autor-data. Entretanto, o estilo Chicago requer obrigatoriamente que a citação indireta inclua a página inicial e final, capítulo ou outra forma de indicação. Regra similar é encontrada no estilo MLA que requer um cuidado maior, visto que se um autor já tiver sido citado no mesmo parágrafo, a próxima citação poderá ser feita de forma mais simples, com a indicação apenas do número 
da página. (AMERICAN PSYCHOLOGICAL ASSOCIATION, 2020b; CITATION..., 2020; MODERN LANGUAGE ASSOCIATION, 2020; UNIVERSITY OF CHICAGO, 2017).

O único estilo que utiliza apenas o formato numérico é o Vancouver. Neste, a citação é feita com número arábico entre parêntesis. (RECOMMENDATIONS..., 2015).

A análise dos estilos incluídos na pesquisa identificou que o estilo mais simples para a citação é o de Vancouver por utilizar o sistema numérico entre parêntesis e que por isso requer pouco espaço e cuidado, a não ser o de manter o vínculo com a lista de referências que pode ser facilitado com o uso de gerenciadores de referências como o Mendeley, End Note e outros. Aliás, estes programas podem ser utilizados para gerenciar referências em vários estilos na elaboração de manuscritos, tornando a vida do autor mais fácil e liberando-o para se preocupar com o conteúdo. (ENDNOTE, 2019; MENDELEY, 2019; PATRIAS, 2007).

\section{REFERÊNCIAS}

As referências são constituídas de elementos essenciais e complementares extraídos do próprio documento. Os elementos essenciais estão estritamente vinculados ao suporte documental e variam, portanto, conforme o tipo. Os elementos complementares constituem informações adicionais aos elementos essenciais que permitem caracterizar melhor os documentos. (ASSOCIAÇÃO BRASILEIRA DE NORMAS TÉCNICAS, 2018; FURASTÉ, 2004).

\subsection{Elementos essenciais e complementares em livros}

Os elementos essenciais na descrição de livros na ISO 690 e na NBR 6023 são: autor, título, subtítulo (se houver), edição (se houver), local, editora e data de publicação e alguns elementos complementares são as medidas, série, bibliografia, paginação inicial e final, total de páginas, ISBN e título original (Quadro 2). (ASSOCIAÇÃO BRASILEIRA DE NORMAS TÉCNICAS, 2018; INTERNATIONAL ORGANIZATION FOR STANDARDIZATION, 2010). 
Quadro 2 - Elementos essenciais e complementares para descrição de livros

\begin{tabular}{|c|c|c|}
\hline \multirow{2}{*}{ Estilo } & \multicolumn{2}{|c|}{ Elementos } \\
\hline & Essenciais & Complementares $^{1}$ \\
\hline ISO 690 & autor, título, subtítulo (se houver), & medidas, série, bibliografia, \\
\hline NBR 6023 & $\begin{array}{l}\text { ediçao (se nouver), local, editora } \\
\text { e data de publicação }\end{array}$ & $\begin{array}{c}\text { pagınaçao Inı́cial e final, } \\
\text { total de páginas, ISBN e } \\
\text { título original }\end{array}$ \\
\hline APA & $\begin{array}{l}\text { autor, data, título e subtítulo } \\
\text { (se houver) e editora }\end{array}$ & Não especificado \\
\hline MLA & $\begin{array}{l}\text { autor, título, subtítulo (se houver), } \\
\text { editora e data }\end{array}$ & $\begin{array}{c}\text { data de publicação original, } \\
\text { o local de publicação (cidade), } \\
\text { data de acesso e URLs } \\
\text { (documentos acessados } \\
\text { online) e DOls. }\end{array}$ \\
\hline Chicago & $\begin{array}{c}\text { autor, data, título, local, editora } \\
\text { e data }\end{array}$ & Não especificado \\
\hline Harvard & $\begin{array}{l}\text { autor, data, título, edição (exceto } \\
\text { primeira edição), local e editora }\end{array}$ & Não especificado \\
\hline CSE & $\begin{array}{c}\text { autor, data, título, local } \\
\text { e editora }\end{array}$ & Não especificado \\
\hline Vancouver & $\begin{array}{c}\text { autor/editor; título; tipo da mídia } \\
\text { (se houver); edição; local de } \\
\text { publicação; editora, data de } \\
\text { publicação e idioma (se diferente } \\
\text { do inglês) }\end{array}$ & Não especificado \\
\hline
\end{tabular}

Nota: 1. Devido à variedade dos tipos documentais, os elementos complementares possuem uma maior variação que torna inviável descrever todos neste quadro.

Fonte: Os autores, 2020.

Em Vancouver, os elementos essenciais são autor/editor; título; tipo da mídia (se houver); edição; local de publicação; editora, data de publicação e idioma (se diferente do inglês). A norma não explicita quais os elementos complementares neste tipo de documento. (NATIONAL LIBRARY OF MEDICINE, 2018).

Os elementos essenciais dos estilos APA, Chicago, Harvard, CSE são os apresentados no Quadro 1. O texto desses estilos não apresentou nenhuma orientação quanto ao uso de elementos complementares ou opcionais. (AMERICAN PSYCHOLOGICAL ASSOCIATION, 2020b; CITATION..., 2020; COUNCIL OF SCIENCE EDITORS, 2020; UNIVERSITY OF CHICAGO, 2017).

No estilo MLA são opcionais a data de publicação original, - local de publicação (cidade), data de acesso e URLs (documentos acessados online) e DOIs. (MODERN LANGUAGE ASSOCIATION, 2020). 
$\mathrm{Na}$ ausência de item específico (comum nos demais estilos) sobre elementos essenciais, entende-se que a própria descrição dos exemplos são os elementos essenciais.

\subsubsection{Elementos essenciais e complementares em periódicos}

Os elementos essenciais na descrição de periódicos podem ser vistos no Quadro 3e nos exemplos de cada estilo. Quanto aos elementos complementares, Vancouver foi o estilo que melhor apresentou os elementos: o mês, número de publicação e a identificação única da referência (periódicos), editora e local de publicação (softwares da internet) (Quadro 3).

Quadro 3 - Elementos essenciais e complementares para descrição de artigos de periódicos

\begin{tabular}{|c|c|c|}
\hline \multirow{2}{*}{ Estilo } & \multicolumn{2}{|c|}{ Elementos } \\
\hline & Essenciais & Complementares $^{1}$ \\
\hline ISO 690 & \multirow{2}{*}{$\begin{array}{l}\text { autor, título do artigo ou da matéria, } \\
\text { subtítulo (se houver), título do } \\
\text { periódico, subtítulo (se houver), local } \\
\text { de publicação, numeração do ano } \\
\text { e/ou volume, número e/ou edição, } \\
\text { tomo (se houver), páginas inicial e } \\
\text { final, e data ou período de publicação }\end{array}$} & \multirow[b]{2}{*}{ Não especificado ${ }^{1}$} \\
\hline NBR 6023 & & \\
\hline APA & $\begin{array}{l}\text { autor, data de publicação, título do } \\
\text { artigo, título do periódico, volume, } \\
\text { número, páginas inicial e final, doi. }\end{array}$ & Não especificado \\
\hline MLA & $\begin{array}{l}\text { autor, título do artigo, título do } \\
\text { periódico, volume, número, data de } \\
\text { publicação, páginas inicial e final. }\end{array}$ & Não especificado \\
\hline Chicago & $\begin{array}{l}\text { autor, data de publicação, título do } \\
\text { artigo, título do periódico, volume, } \\
\text { número, páginas inicial e final, doi. }\end{array}$ & Não especificado \\
\hline Harvard & $\begin{array}{l}\text { autor, data de publicação, título do } \\
\text { artigo, título do periódico, volume, } \\
\text { número, páginas inicial e final. }\end{array}$ & Não especificado \\
\hline CSE & $\begin{array}{l}\text { autor, data de publicação, título do } \\
\text { artigo, título do periódico, volume, } \\
\text { número, páginas inicial e final. }\end{array}$ & Não informado \\
\hline Vancouver & $\begin{array}{c}\text { autor, título do artigo, título do } \\
\text { periódico, data de publicação, } \\
\text { volume, número, páginas inicial e } \\
\text { final. }\end{array}$ & $\begin{array}{l}\text { o mês, número de publicação e a } \\
\text { identificação única da referência } \\
\text { (periódicos), editora e local de } \\
\text { publicação (softwares da internet). }\end{array}$ \\
\hline
\end{tabular}

Nota: 1. As normas não deixam claro quais os elementos complementares. Para identificá-los é preciso um exercício de interpretação.

Fonte: Os autores, 2020.

Independente da forma como as referências forem construídas - se com uso de elementos complementares - uma sequência lógica dos elementos deverá ser obedecida. 


\subsection{Sequência dos elementos: aspecto geral}

$\mathrm{Na}$ construção mental sobre a estrutura que compõe uma referência de um livro, a imagem comum que temos é a seguinte: Autor. Título. Edição. Local. Editora. Data. Número de páginas. Na repetição do exercício mental para artigo de periódico, a imagem construída será mais ou menos essa: Autor. Título do artigo. Título da revista. Volume, número, paginação e data (Quadro 4).

Quadro 4 - Sequência básica da descrição de um livro (superior) e artigo de periódico (inferior)

Autor. Título. Edição. Local. Editora. Data. Total de páginas.

Autor. Título. Nome da revista. Volume, Número, paginação.Data.

Fonte: O autor, 2020

As duas construções do Quadro 4 são bem elementares. Apenas fornecem uma linha geral de direcionamento na construção de referências e, portanto, não representam a variação encontrada nos estilos apresentados neste artigo.

Em relação ao início da referência, independente do tipo documental, todos os estilos incluídos na pesquisa foram unânimes em iniciar a descrição do documento com a definição da autoria. As diferenças na apresentação deste elemento estão relacionadas ao uso ou não de caixa alta na representação do sobrenome e que são abordadas no item específico (Autor).

Contudo, para manutenção da qualidade de uma referência, é necessário estabelecer uma sequência lógica e normalizada dos elementos a fim de garantir o fiel cumprimento dessa sequência na descrição dos recursos bibliográficos.

\subsubsection{Sequência dos elementos nos livros}

Os estilos são similares na descrição do elemento autor. Contudo, é a partir deste campo que as diferenças começam a surgir.Enquanto as normas ISO 690, 6023, MLA e Vancouver dão sequência com a descrição do título do livro ou do artigo, os estilos APA, Chicago, Harvard e CSE optam por descrever o ano de publicação com variações seguidas da descrição do título (Quadro 5). (AMERICAN PSYCHOLOGICAL ASSOCIATION, 2020b; ASSOCIAÇÃO BRASILEIRA DE NORMAS TÉCNICAS, 2018; CITATION..., 2020; COUNCIL OF SCIENCE EDITORS, 2020; INTERNATIONAL ORGANIZATION FOR STANDARDIZATION, 
2010; MODERN LANGUAGE ASSOCIATION, 2020; NATIONAL LIBRARY OF MEDICINE, 2018; UNIVERSITY OF CHICAGO, 2017).

Quadro 5 - Relação das referências de livro e artigo de periódico utilizando elementos essenciais com os estilos

\begin{tabular}{|c|c|}
\hline Estilo & Referência \\
\hline $\begin{array}{l}\text { ISO } \\
690: 2010(E)\end{array}$ & $\begin{array}{l}\text { Livro } \\
\text { SOBRENOME, Prenome. Título. } \\
\text { Edição (exceto primeira edição). Local: } \\
\text { Editora, Data. } \\
\text { Artigo de periódico } \\
\text { SOBRENOME, Prenome.Título do } \\
\text { artigo.Título do periódico,volume, } \\
\text { número, página inicial-final,Ano de } \\
\text { publicação. }\end{array}$ \\
\hline 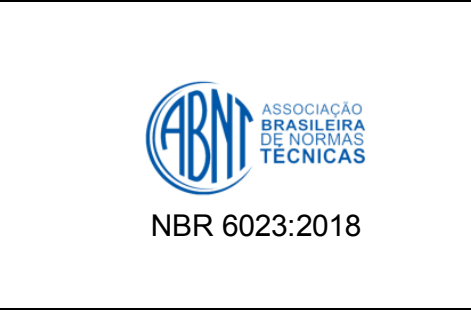 & $\begin{array}{l}\text { Livro } \\
\text { SOBRENOME, Prenome. Título. } \\
\text { Edição (exceto primeira edição). Local: } \\
\quad \text { Editora, Data. } \\
\text { Artigo de periódico } \\
\text { SOBRENOME, Prenome.Título do } \\
\text { artigo.Título do periódico,volume, } \\
\text { número, página inicial-final,Ano de } \\
\text { publicação. }\end{array}$ \\
\hline APA & $\begin{array}{l}\text { Livro } \\
\text { Sobrenome, Inicial do nome. (Data). } \\
\quad \text { Título. Editora. } \\
\text { Artigo de periódico } \\
\text { SOBRENOME, Inicial do prenome.(Ano } \\
\text { de publicação). Título do artigo. Título do } \\
\quad \text { periódico,volume(número), } \\
\text { páginainicial-final. Doi }\end{array}$ \\
\hline \& MLA Style Center & $\begin{array}{l}\text { Livro } \\
\text { Sobrenome, Prenome. Título. Editora, } \\
\text { Data. } \\
\text { Artigo de periódico } \\
\text { Sobrenome, Prenome. "Título do } \\
\text { artigo."Título do periódico,volume, } \\
\text { número, Ano de publicação, página } \\
\text { inicial-final. }\end{array}$ \\
\hline $\begin{array}{l}\text { The } \\
\text { Chicago } \\
\text { Manual } \\
\text { of Style } \\
\text { Online }\end{array}$ & $\begin{array}{l}\text { Livro } \\
\text { Sobrenome, Prenome. Data. Título. } \\
\text { Local: Editora, Data. } \\
\text { Artigo de periódico } \\
\text { Sobrenome, Prenome.Ano de } \\
\text { publicação. "Título do artigo."Título do } \\
\text { periódicovolume, número, página } \\
\quad \text { inicial-final.Doi }\end{array}$ \\
\hline
\end{tabular}




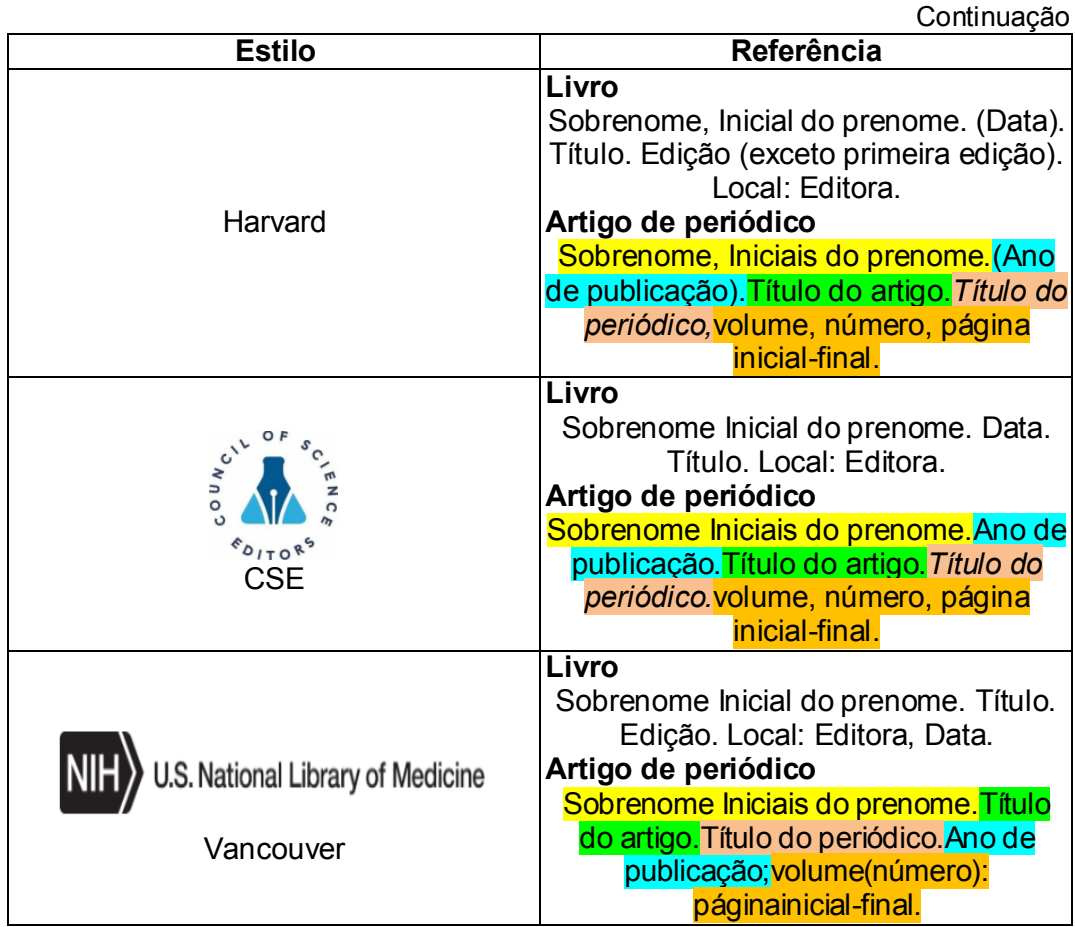

Nota: 1. As referências foram elaboradas sem a aplicação dos critérios de alinhamento e espaçamento.

2. Não houve a aplicação do recuo nas referências que tiveram continuação na linha inferior

Fonte: O autor, 2020.

A descrição do ano de publicação logo após a definição da autoria (APA, Chicago, Harvard e CSE) visa facilitar a identificação imediata da atualização do documento. Estilo que se aproxima do formato das citações utilizadas no formato autor-data utilizado pela maioria dos estilos aqui analisados. (AMERICAN PSYCHOLOGICAL ASSOCIATION, 2020b; CITATION..., 2020; COUNCIL OF SCIENCE EDITORS, 2020; UNIVERSITY OF CHICAGO, 2017).

Após a definição do título, ocorrem as diferenças normais alinhadas ao tipo documental. Por exemplo, na descrição do livro como um todo, o estilo APA não exige a inclusão do local de publicação. Em outros não há necessidade de incluir a edição do documento e todos não exigiram a descrição do número de páginas do documento (livro) (Quadro 5). (AMERICAN PSYCHOLOGICAL ASSOCIATION, 2020b). 
4.2.2 Sequência dos elementos nos artigos de periódicos

Os estilos ISO 690(E) e NBR 6023 possuem a mesma ordem de apresentação dos elementos: Autoria. Título. Edição. Local. Editora e Data (livros) e Autoria. Título do artigo. Nome da revista (Quadro 5). (ASSOCIAÇÃO BRASILEIRA DE NORMAS TÉCNICAS, 2018; INTERNATIONAL ORGANIZATION FOR STANDARDIZATION, 2010).

Já os estilos APA, MLA, Chicago, CSE, Harvard e Vancouver possuem algumas variações tais como a data de publicação antecedendo a descrição do título (APA, Chicago, CSE e Harvard); fechando a referência após a paginação (MLA) ou ao final da referência (Vancouver).No caso de livros e artigos de periódicos, os estilos Chicago e APA exigem que seja informado o número do DOI (Quadro 5). (AMERICAN PSYCHOLOGICAL ASSOCIATION, 2020b; CITATION..., 2020; MODERN LANGUAGE ASSOCIATION, 2020; NATIONAL LIBRARY OF MEDICINE, 2018; UNIVERSITY OF CHICAGO, 2017).

Além da sequência lógica a ser obedecida pelos elementos, a lista com a descrição dos documentos deverá também seguir orientações quanto ao alinhamento e espaçamento para manteremse organizadas e ocuparam o espaço estritamente necessário.

\subsection{Alinhamento e Espaçamento}

O alinhamento e o espaçamento entre as referências visam manter o ordenamento alfabético ou numérico e permitir que o texto fique esteticamente agradável.

Os únicos estilos que abordam explicitamente e de forma detalhada questões quanto ao alinhamento e espaçamento são a ISO 690 e a NBR 6023:2018. Em ambas, o alinhamento deve ser feito à margem esquerda. (ASSOCIAÇÃO BRASILEIRA DE NORMAS TÉCNICAS, 2018; INTERNATIONAL ORGANIZATION FOR STANDARDIZATION, 2010).

As referências devem ser construídas com espaçamento simples e uma linha em branco com espaçamento simples deve ser usada para separar as referências. As orientações quanto ao alinhamento e espaçamento estendem-se para as referências utilizadas em notas de rodapé. Neste caso, além de serem alinhadas à margem esquerda do texto, devem ser elaboradas a partir da segunda linha da mesma referência, abaixo da primeira letra da primeira palavra, de forma a destacar o expoente e sem espaço entre elas. (ASSOCIAÇÃO BRASILEIRA DE NORMAS TÉCNICAS, 2018; INTERNATIONAL ORGANIZATION FOR 
STANDARDIZATION, 2010).

A linha em branco de espaço simples entre referências não impede o ordenamento alfabético como comando "Classificar" do Word. No entanto, se este recurso for aplicado após a inclusão de todas as referências na lista, haverá necessidade de se fazer a separação manual de cada uma das referências a fim de manter uma linha em branco entre elas.

Neste sentido, a fim de solucionar este problema, sugere-se a adoção de gerenciadores de referências disponíveis no mercado. Alguns são gratuitos e outros que exigem uma assinatura. (MENDELEY, 2019).

Pode ser questionável a fixação de norma para formatar o alinhamento e o espaçamento das referências. Contudo, o outro extremo (a ausência de orientação) pode deixar 0 autor de manuscritos em dúvida quanto ao formato a ser utilizado. Por exemplo, o estilo APA não possui uma orientação expressa quanto ao alinhamento e o espaçamento. A definição ocorre pela análise lógica dos exemplos citados no texto. Neste caso, poderia haver ao menos uma menção de que tal situação ficaria a critério do autor. (AMERICAN PSYCHOLOGICAL ASSOCIATION, 2020b; ASSOCIAÇÃO BRASILEIRA DE NORMAS TÉCNICAS, 2018).

\subsection{Pontuação}

Diferente da omissão pela maioria dos estilos quanto ao alinhamento e espaçamento, os estilos são bem claros quanto à pontuação utilizada. Na análise, observaram-se diferenças sutis em cada um dos estilos. Para descrever, por exemplo, o elemento autoria pessoal, os estilos ISO 690 e 6023 são idênticos. Ambos utilizam o ponto, a vírgula e o ponto e vírgula para marcarem a abreviação dos prenomes e para finalizar a descrição do campo; separar o nome do prenome e os autores respectivamente. Aliás, o uso do ponto e vírgula aparece somente nestes dois estilos (Quadro 6). (ASSOCIAÇÃO BRASILEIRA DE NORMAS TÉCNICAS, 2018; INTERNATIONAL ORGANIZATION FOR STANDARDIZATION, 2010). 
Quadro 6 - Exemplo de descrição de autoria pessoal (um autor) com destaque para o uso de caixa alta na ISO 690 e NBR 6023.

\begin{tabular}{|c|c|}
\hline $\mathbf{6 9 0}$ & NRB 6023 \\
\hline PEDROSA, V. L. & PEDROSA, V. L. \\
\hline APA & MLA \\
Pedrosa, V.L. & Pedrosa, Valderiza \\
\hline Chicago & Harvard \\
Pedrosa, Valderiza & Pedrosa, V. \\
\hline CSE & Vancouver \\
Pedrosa VL & Pedroza VL \\
\hline
\end{tabular}

Fonte: $\mathrm{O}$ autor, 2020.

Nos demais estilos, ainda em relação à descrição da autoria pessoal, verificou-se a utilização do ponto, a vírgula, o conectivo and (Chicago) e, em alguns casos o sinal e comercial " $\&$ " e as reticências (Estilo APA) (Quadro 7). (AMERICAN PSYCHOLOGICAL ASSOCIATION, 2020b; UNIVERSITY OF CHICAGO, 2017).

Quadro 7- Exemplo de descrição de autoria pessoal (dois ou mais autores) com destaque para os conectores nos estilos APA, MLA e Harvard.

\begin{tabular}{|c|c|}
\hline 690 & NRB 6023 \\
PEDROSA, V. L.; SACHETT, J. & PEDROSA, V. L.; SACHETT, J. \\
\hline APA & MLA \\
Pedrosa, V.L, \&Sachett, J. & $\begin{array}{c}\text { Pedrosa, Valderiztand } \\
\text { Jaqueline Sachett }\end{array}$ \\
\hline Chicago & Harvard \\
Pedrosa, Valderiza, Jaqueline Sachett & Pedrosa, V and Sachett, J. \\
\hline CSE & Vancouver \\
Pedrosa VL, Sachett J. & Pedroza VL, Sachett J. \\
\hline
\end{tabular}

Fonte: $\mathrm{O}$ autor, 2020.

Em geral, percebe-se que os estilos ISO 690 e 6023 utilizam em demasia as pontuações, principalmente na descrição da autoria pessoal e nas abreviações. Excesso que não é visto nos demais estilos. (ASSOCIAÇÃO BRASILEIRA DE NORMAS TÉCNICAS, 2018; INTERNATIONAL ORGANIZATION FOR STANDARDIZATION, 2010).

Nota-se semelhança entre os estilos CSE e Vancouver. No entanto, essa semelhança se desfaz quando o documento possui mais de sete autores (Vancouver) e mais de 11 autores (CSE), no qual são utilizados a expressão "et al". Enfim, não é objetivo do artigo se estender na descrição da pontuação utilizada para descrever os vários elementos que compõe uma referência. $\mathrm{Na}$ escolha de um dos estilos para a descrição, sugere-se a consulta 
ao texto original. (COUNCIL OF SCIENCE EDITORS, 2020; NATIONAL LIBRARY OF MEDICINE, 2018).

\subsection{Autor pessoa física}

Autor pessoa física são pessoa(as) responsável(eis) pela criação do conteúdo intelectual ou artístico de um documento. É o primeiro elemento de uma referência (Quadro 4). (ASSOCIAÇÃO BRASILEIRA DE NORMAS TÉCNICAS, 2018). Este item visa demonstrar a forma como os estilos orientam a descrição desse elemento assim como a pontuação utilizada.

$\mathrm{Na}$ descrição da autoria dos documentos, os estilos da ISO 690 e NBR 6023 são idênticos (Quadro 7), tanto na ordem dos elementos quanto na formatação dos mesmos. É claro que seria de se esperar essa similaridade, pois, apesar da nova versão da NBR 6023 não fazer referência à utilização da ISO 690 para sua elaboração, a versão publicada em 2018 possui muitos itens similares à ISO 690. Ambas são as únicas que utilizam caixa alta para descrever o sobrenome dos autores individuais e institucionais. (ASSOCIAÇÃO BRASILEIRA DE NORMAS TÉCNICAS, 2018; INTERNATIONAL ORGANIZATION FOR STANDARDIZATION, 2010).

Entende-se que o uso da caixa alta visa proporcionar maior destaque aos sobrenomes de autores pessoais e autoria institucional. No entanto, o problema com esse formato de descrição - o uso de caixa alta - é que ele costuma tomar mais espaço se comparado com os demais estilos além de ser, em certo grau,visualmente inconveniente, pois ao utilizar a caixa alta, parece que estamos diante de uma espécie de alerta maior para chamar mais a atenção.

Aliás, com a nova versão da norma, que permite a inclusão de todos os autores de uma obra (imagine-se a extensão de uma referência de um texto com 10, 15 ou 20 autores onde opta-se pela inclusão de todos na referência), ter-se-á uma referência demasiada longa e com necessidade de mais espaço (Tabela 1). (ASSOCIAÇÃO BRASILEIRA DE NORMAS TÉCNICAS, 2018).

A explicação para o fato do texto da nova versão ter mantido o uso de caixa alta não encontra explicação em nenhum texto científico. Este fato pode ser explicado apenas por conjecturas que levam em consideração a relação institucional regida por contrato que a NBR6023 possui em relação à ISO 690. Outra explicação possível seria o fato ou desejo de se manter única entre todos os estilos. Enfim, esta é uma lacuna que o artigo não tentou resolver, ficando apenas uma questão a ser analisada em futuros trabalhos. 
Tabela 1 - Recorte comparativo entre NBR 6023 e Vancouver de referência de artigo periódico com 6 autores com percentual de palavras

\begin{tabular}{|c|c|}
\hline \multicolumn{2}{|c|}{ Estilo } \\
\hline $\begin{array}{c}\mathbf{6 0 2 3} \\
\text { STEGLICH, Raquel Bisscotti; } \\
\text { CARDOSO, Silvana; CESTARI, } \\
\text { Tânia Ferreira; COELHO, Karina } \\
\text { Munhoz de Paula Alves; } \\
\text { GAERTNER, Maria Helena da Costa } \\
\text { Naumann; FRANCO, Selma } \\
\text { Cristina. Aspectos epidemiológicos e } \\
\text { histopatológicos do melanoma } \\
\text { cutâneo primário em residentes de } \\
\text { Joinville, 2003-2014. An. } \\
\text { BrasDermatol, v.93, n.1, p.50-58, } \\
2018 .\end{array}$ & $\begin{array}{c}\text { Vancouver } \\
\text { Steglich RB Cardoso S, Cestari TF, } \\
\text { Coelho KM, Gaertner MH, Franco } \\
\text { SC. Aspectos epidemiológicos e } \\
\text { histopatológicos do melanoma } \\
\text { cutâneo primário em residentes de } \\
\text { Joinville, 2003-2014. } \\
\text { AnBrasDermatol. 2018; 93(1):50-58. }\end{array}$ \\
\hline Total de palavras: 43 & Total de palavras: $30(69 \%)$ \\
\hline $\begin{array}{l}\text { Notas: 1. O total de palavras utilizado no e } \\
\text { utilizado no formato NBR } 6023 \text {. } \\
\text { 2. O resultado é apenas um recorte } \\
\text { estudo aprofundado. } \\
\text { Fonte: O autor, } 2020 \text {. }\end{array}$ & stilo Vancouver foi $69 \%$ menor aue \\
\hline
\end{tabular}

\subsubsection{Formatação dos prenomes}

Na ISO 690 e na NBR 6023 há flexibilidade na descrição que pode ser abreviada ou completa. No caso de utilização da forma abreviada, deverá ser utilizado o ponto para marcar a abreviação (Quadro 6). (ASSOCIAÇÃO BRASILEIRA DE NORMAS TÉCNICAS, 2018; INTERNATIONAL ORGANIZATION FOR STANDARDIZATION, 2010).

Enquanto os estilos MLA e Chicago utilizam somente a forma completa para os prenomes, a APA, CSE, Vancouver e Harvard utilizam a forma abreviada. As três primeiras não utilizam o ponto para marcar a abreviação (Quadro 6 e Quadro 7). (AMERICAN PSYCHOLOGICAL ASSOCIATION, 2020b; CITATION..., 2020; COUNCIL OF SCIENCE EDITORS, 2020; MODERN LANGUAGE ASSOCIATION, 2020; NATIONAL LIBRARY OF MEDICINE, 2018; UNIVERSITY OF CHICAGO, 2017).

Utilizar a forma abreviada traz a vantagem de se ter uma referência que ocupa menos espaço pela sua simplificação. Em contrapartida, o uso desse recurso "esconde" os prenomes dos autores que em alguns casos pode ser necessário conhecer num universo enorme de autores que já estão nesse círculo de 
publicações, sem considerar os outros que diariamente se inserem nesse círculo do conhecimento. $\mathrm{E}$, caso $\mathrm{O}$ documento principalmente para artigos de periódicos - esteja em construção sem a definição de onde será submetido, sugere-se a utilização da forma completa para autores. Assim, após a escolha da revista, caso seja necessário ajuste no sentido de abreviar os prenomes, bastará fazer isso manualmente e, no caso inverso, o texto estará ajustado para ser submetido.

\subsubsection{Autor pessoa física: uso do "et al"}

Os oito estilos foram analisados em relação ao uso da expressão "et al" exclusivamente na lista de referências. Não foi incluída a análise da utilização da expressão nas citações. Neste caso, recomenda-se a consulta ao documento original dos estilos.

Apenas cinco dos oito estilos analisados (ISO 690, NBR 6023, MLA, CSE e Vancouver) utilizam o "et al". A ISO 690 e a NBR 6023 o fazem quando o documento tiver mais de três autores. Contudo, na versão de 2018 da NBR 6023 é possível descrever todos os autores. A mesma possibilidade é encontrada na MLA onde todos os autores podem ser incluídos de acordo com a regra para dois a três autores ou descrever apenas o primeiro autor seguido da expressão "et a". (ASSOCIAÇÃO BRASILEIRA DE NORMAS TÉCNICAS, 2018; COUNCIL OF SCIENCE EDITORS, 2020; INTERNATIONAL ORGANIZATION FOR STANDARDIZATION, 2010; MODERN LANGUAGE ASSOCIATION, 2020; NATIONAL LIBRARY OF MEDICINE, 2018).

No caso da CSE, o uso do "et al" fica condicionado à descrição de documentos que apresentam mais de 10 autores e no estilo Vancouver, utiliza-se quando o documento tiver mais de seis autores. (COUNCIL OF SCIENCE EDITORS, 2020).

Nos demais estilos (APA, Chicago e Harvard) a descrição de documentos com vários autores ocorre com o uso de símbolos como o e comercial (\&) e reticências (...) (APA), utilização da ordem direta dos nomes dos autores (Chicago) e o uso de artigos de ligação "and" (Harvard). (AMERICAN PSYCHOLOGICAL ASSOCIATION, 2020b; CITATION..., 2020; UNIVERSITY OF CHICAGO, 2017).

Para o pesquisador é gratificante ver um artigo seu publicado assim como também é gratificante ver seu nome publicado e não escondido pelo "et al" em listas de referências. É muito comum hoje em algumas áreas do conhecimento a existência de artigos contendo 4, 5, 10 ou mais autores. A regra que estabelece o uso do "et al" imediatamente em documentos com mais de três autores - 
ISO 690 e NBR 6023 - apesar de possibilitar uma referência mais enxuta, limita a exposição dos demais autores que participaram da elaboração do documento. (ASSOCIAÇÃO BRASILEIRA DE NORMAS TÉCNICAS, 2018; INTERNATIONAL ORGANIZATION FOR STANDARDIZATION, 2010).

\subsubsection{Destaque tipográfico}

A orientação quanto ao uso do destaque tipográfico (negrito, sublinhado ou itálico) está presente na ISO 690 e na NBR 6023. Nesses dois estilos, assim como nos demais analisados - exceto CSE e Vancouver - o destaque tipográfico é utilizado obrigatoriamente para evidenciar o título da obra (livros) e o nome da revista (artigos de periódicos). (ASSOCIAÇÃO BRASILEIRA DE NORMAS TÉCNICAS, 2018; INTERNATIONAL ORGANIZATION FOR STANDARDIZATION, 2010).

Na ISO 690 e na NBR 6023 a utilização pode-se optar por um dos três tipos de destaque. Nos demais estilos (APA, MLA, Chicago e Harvard) o destaque tipográfico utilizado como padrão é o itálico. No estilo Chicago, o uso do itálico é aplicado para destacar o título e o subtítulo da obra (se houver). (AMERICAN PSYCHOLOGICAL ASSOCIATION, 2020b; ASSOCIAÇÃO BRASILEIRA DE NORMAS TÉCNICAS, 2018; CITATION..., 2020; INTERNATIONAL ORGANIZATION FOR STANDARDIZATION, 2010; MODERN LANGUAGE ASSOCIATION, 2020; UNIVERSITY OF CHICAGO, 2017).

\subsubsection{Abreviações dos títulos dos periódicos}

No texto e nos exemplos da NBR 6023:2018 os títulos das publicações periódicas podem ser transcritos de duas formas: completa ou abreviada. A norma orienta que a forma abreviada deve ser usada desde que conste na publicação. Até 2018 havia uma norma brasileira específica (NBR 6032) para abreviação de títulos de periódicos, mas que foi cancelada pela ABNT em 08/01/2010. (ASSOCIAÇÃO BRASILEIRA DE NORMAS TÉCNICAS, 2018).

Orientação similar às normas ISO 690 e NBR 6023 ocorrem nos estilos CSE e Vancouver, mas sem a utilização do ponto para a marcação. Já os estilos APA, MLA, Chicago e Harvard orientam a descrição na forma completa. (ASSOCIAÇÃO BRASILEIRA DE NORMAS TÉCNICAS, 2018; INTERNATIONAL ORGANIZATION FOR STANDARDIZATION, 2010).

O estilo de Vancouver possui um catálogo online que fornece acesso aos dados bibliográficos de mais de 1,4 milhão de periódicos, 
livros, audiovisuais e outros materiais. Nele é possível pesquisar por tópico, título do periódico na forma completa ou pela abreviação do mesmo e pelo ISSN (Figura 5). (NLM CATALOG..., 2010)

Figura 5 - Base de dados do NCBI para identificação de abreviação de periódicos

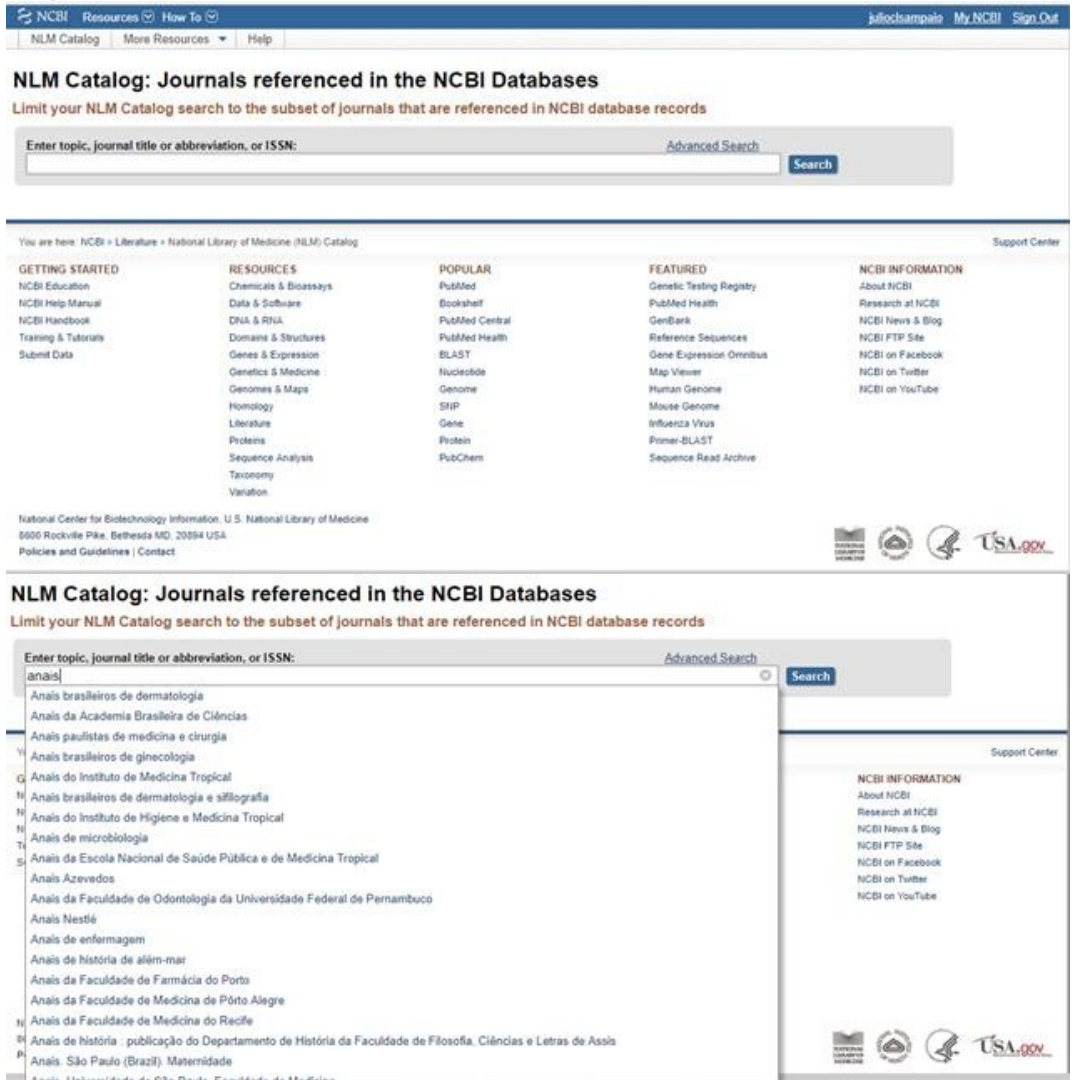

Fonte: NLM CATALOG...(2010).

\section{CONCLUSÃO}

Referenciar é estabelecer um conjunto padronizado de elementos descritivos, retirados de um documento (livro impresso, e-book, DVD, CD, registro audiovisual, tridimensional e outros) para permitir sua identificação individual a qualquer pessoa. Um documento bem referenciado reveste 0 trabalho de 
consistência e credibilidade com as ideias, conceitos e conclusões de outros autores por meio de citações no texto construídas conforme um estilo definido aplicável em determinada área do conhecimento.

A análise dos oito estilos evidenciou que a maioria utiliza o sistema autor-data para citação com leves variações. A única exceção foi encontrada no estilo de Vancouver que utiliza o sistema numérico.

Ordem dos elementos parece ser universal, pois todos iniciaram a descrição da referência pelo autor pessoa física com pequenas diferenças entre os estilos. É necessário atenção nas regras do estilo escolhido para a elaboração e formatação do manuscrito.

Quanto aos elementos essenciais, parece não haver uma preocupação em deixar claro quais são esses elementos. A exceção ocorreu na NBR 6023 e na ISO 690. A mesma lacuna foi encontrada nas orientações quanto ao alinhamento e espaçamento. Novamente as normas ISO 690 e NBR 6023 se destacaram por descrever o alinhamento à esquerda do texto e uso do espaçamento simples, que não impede a ordenação alfabética.

A pontuação foi outro aspecto relevante. A NBR 6023 e a ISO 690 utilizam bastante a pontuação, seja para abreviação ou para separar autores. Os demais estilos não utilizam tanta pontuação para a descrição.

Em relação ao destaque tipográfico e o uso do "et al", a maioria dos estilos usa o itálico para a identificação do título do livro e título da revista e uso do "et al" apresentou uma variação significativa entre os estilos. Neste caso, é louvável a alteração feita na última versão da NBR 6023 que possibilitou a inclusão de todos os autores. Contudo, a manutenção do uso de caixa alta na descrição desse elemento pode tornar extensas as listas de referências. Neste caso, os demais estilos merecem destaque, visto não utilizarem caixa alta em suas descrições.

$\mathrm{Na}$ elaboração de manuscritos, sugere-se ainda a utilização de gerenciadores de referências que facilitam a vida do autor. Alguns são gratuitos e outros de custo bem acessível, mas que vale a pena a instalação e uso.

Em geral, verificou-se que os estilos APA, CSE, MLA, Chicago, Harvard e Vancouver são mais simples. Estes ocupam menos espaço e favorecem a publicação de mais conteúdo sem perder a qualidade das informações. Além disso, alguns são gratuitos ou de custo acessível em relação às normas ISO 690 e NBR 6023, além de serem amplamente aceitos e com atualização constante. 


\section{REFERÊNCIAS}

AMERICAN PSHYCOLOGICAL ASSOCIATION. Publication manual of the American Psychological Association, Seventh Edition (2020).7th. [S.I.]: APA, 2020. Disponível em: https://apastyle.apa.org/products/publicationmanual-7th-edition. Acesso: 2 jan. 2020.

AMERICAN PSYCHOLOGICAL ASSOCIATION. APA history. Disponível em: https://www.apa.org/about/apa/archives/apa-history. c2020a Acesso em: 12 jan. 2020.

AMERICAN PSYCHOLOGICAL ASSOCIATION. APA style. c2020b Disponível em: https://apastyle.apa.org/index?_ga=2.111775172. 156938083.1578924904-536513828.1578583699. Acesso em: 12 jan. 2020.

ASSOCIAÇÃO BRASILEIRA DE NORMAS TÉCNICAS. ABNT catálogo. Disponível em: http://www.abnt.org.br/normalizacao/abnt-catalogo. Acesso em: 15 jan. 2019.

ASSOCIAÇÃO BRASILEIRA DE NORMAS TÉCNICAS. Elaboração e participação. Disponível em: http://www.abnt.org.br/normalizacao/ elaboracao-e-participacao/como-se-elaboram. Acesso em: 12 jan. 2020.

ASSOCIAÇÃO BRASILEIRA DE NORMAS TÉCNICAS. NBR 10520: informação e documentação: citações em documentos: apresentação. Rio de Janeiro, 2002.

ASSOCIAÇÃO BRASILEIRA DE NORMAS TÉCNICAS. NBR 6023: informação e documentação: referênias: elaboração. Rio de Janeiro, 2018.

BIBLIOTECA JOSÉ DE ALENCAR. ABNT 6023:2018: mudança na norma brasileira sobre elaboração de referências. Disponível em: https://letras.biblioteca.ufrj.br/mudancas-na-norma-da-abnt-6023-queorienta-a-elaboracao-de-referencias/. Acesso em: 12 jan. 2020.

BRKIC, S.; PEJIC, M. The Vancouver regulations and publishing is biomedical journals. Med. Pregl. v. 49, n. 1-2, p. 27-31, 1996.

CHERNIN, E. The "Harvard system": a mysteri dispelled. Br. Med. J. v. 297, p.1062-1063, 1988. Disponível em: http://www.uefap.com/writing/referenc/ harvard.pdf. Acesso em: 12 jan. 2020.

CITATION AND RESEARCH MANAGEMENT TOOLS AT HARVARD. Disponível em: https://guides.library.harvard.edu/cite/guides. Acesso em: 9 jan. 2020.

COUNCIL OF SCIENCE EDITORS. Scientific style and format. Disponível em: https://www.councilscienceeditors.org/publications/scientific-style-andformat/. Acesso em: 12 jan. 2020.

ENDNOTE. Disponível em: https://endnote.com/. Acesso em: 3 jan. 2020.

FURASTÉ, P. A. Normas técnicas para o trabalho científico. 13.ed. Porto 
Alegre: [s.n], 2004. 185 p.

GOSLING, P. H. Vancouver style. Br. Med. J. v. 1, n. 6169, p. 1019, 1979.

Disponível em: https://www.ncbi.nlm.nih.gov/pmc/articles/PMC1598632/. Acesso em: 4 jan. 2020.

INTERNATIONAL ORGANIZATION FOR STANDARDIZATION. ISO 690: information and documentation: guidelines for bibliographic references and citations to information resources. Geneva, 2010.

INTERNATIONAL STEERING COMMITTEE OF MEDICAL EDITORS. Uniform requirements for manuscripts submitted to biomedical journals. $\mathbf{B r}$. Med. J. v. 1, n. v.1, p.1334-6, p. 1334-1336, 1978.

INTERNATIONAL STEERING COMMITTEE OF MEDICAL EDITORS. Uniform requirements for manuscripts submitted to biomedical journals. $\mathbf{B r}$. Med. J. v. 1, p. 523-525, 1979.

ISO 690. Cad. Apoio Utiliz. v. 3, n. 6, p. 1-15, 2012. Disponível em: https://repositorio.iscte-iul.pt/bitstream/10071/15070/1/Guia_Referências Bibliográficas_ISO 690.pdf. Acesso em: 12 jan. 2020.

MENDELEY. Disponível em: https://www.mendeley.com/?interaction_ required=true. Acesso em: 2 jan. 2020.

MODERN LANGUAGE ASSOCIATION. MLA handbook. 8th. New York: MLA, 2016. Disponivel em: https://www.mla.org/Publications/Bookstore/ Nonseries/MLA-Handbook-Eighth-Edition.

MODERN LANGUAGE ASSOCIATION. MLA style. Disponível em: https://www.mla.org/MLA-Style. Acesso em: 12 jan. 2020.

MODERN LANGUAGE ASSOCIATION; THE MLA STYLE CENTER. The history of MLA style, 1931-2016. Disponivel em: https://www.mla. org/About-Us/About-the-MLA/MLA-Archives/Time-Lines/MLA-Style.

Acesso em: 12 jan. 2020.

MONTEIRO, S. D. Estudo comparativo das normas técnicas de documentação: uma atualização. Inf.Inf. v. 2, n. 1, p. 7-28, 1997. Disponível em: http://www.uel.br/revistas/uel/index.php/informacao/article/view/1607/ 1362. Acesso em: 12 jan. 2020.

NATIONAL INFORMATION STANDARDS INSTITUTE. ANSI/NISO Z39.292005(R2010): bibliographic references. Baltimore, 2010.

NATIONAL LIBRARY OF MEDICINE. Samples of formatted references for authors of journal articles: updated 26 Apr. 2018. Disponível em: https://www.nlm.nih.gov/bsd/uniform_requirements.html. Acesso em: 15 jan. 2020.

NLM CATALOG: journals referenced in the ncbi databases.Disponível em: https://www.ncbi.nlm.nih.gov/nlmcatalog/journals. Acesso em: 12 jan. 2020.

PATRIAS, K. Citing medicine: the NLM style guide for authors, editors, and publishers: updated 2015 Oct 2. 2.ed. Bethesda: National Library of Medicine (US), 2007. Disponível em:http://www.nlm.nih.gov/citingmedicine. 
Acesso em: 2 jan. 2020.

RECOMMENDATIONS for the Conduct, Reporting, Editing, and Publication of Scholarly Work in Medical Journals, 2015. Disponivel em: http://www.icmje.org/icmje-recommendations.pdf. Acesso em: 2 jan. 2019.

SHERRINGTON, A. Declaration of Vancouver updated. Can. Med. Assoc. J. v. 126, n. 8, p. 888-889, 1982. Disponivel em: https://www.ncbi.nlm.nih. gov/pubmed/20313713. Acesso em: 15 jan. 2020.

STYLE of references standardised. N. Engi. J. Med v. 282, p. 49, 1970.

THE CHICAGO MANUAL OS STYLE ONLINE. About the Chicago manual of style. Disponível em: https://www.chicagomanualofstyle.org/help-tools/ about.html. Acesso em: 10 jan. 2020.

THE DECLARATION of Vancouver. Med. J. August. v. 2, n. 4, p. 181, 1979.

THE MLA STYLE CENTER. Works cited: a quick guide. Disponível em: https://style.mla.org/works-cited-a-quick-guide/. Acesso em: 11 jan. 2020.

THE VANCOUVER style. Gut. p. 651-652, 1978. Disponível em: https://www.ncbi.nlm.nih.gov/pmc/articles/PMC1412541/pdf/gut00453-0015.pdf. Acesso em: 2 jan. 2020.

UNIVERSITAT D'ALICANTE; BIBLIOTECA UNIVERSITARIA. La norma ISO 690:2010(E). Alicante, ES: [s.n.]. Disponível em: http://werken.ubiobio. cl/html/downloads/ISO_690/Guia_Breve_ISO690-2010.pdf. , 2017

UNIVERSITY LIBRARY. Guide to Harvard style of referencing. Disponível em: https://library.aru.ac.uk/referencing/files/Harvard_referencing_201920.pdf. Acesso em: 5 jan. 2020.

UNIVERSITY OF CHICAGO. The Chicago manual of style online.17th. Chicago: University of Chicago, 2017. Disponivel em: https://www.chicagomanualofstyle.org/book/ed17/part1/ch01/toc.html.

Recebido em: 09/04/2019

Aceito em: 20/11/2019 